\title{
An Investigation of the Effect of Ship Capacity to Shipping Emissions
}

\author{
Levent Bilgili*, Ugur Bugra Celebi
}

Department of Naval Architecture and Marine Engineering, Naval Architecture and Maritime Faculty, Yildiz Technical University, Turkey

Copyright $(2017$ by authors, all rights reserved. Authors agree that this article remains permanently open access under the terms of the Creative Commons Attribution License 4.0 International License

\begin{abstract}
Shipping has the major part of world trading with a ratio of approximately $90 \%$. Besides their great benefits on economy, shipping activities are responsible for considerable amounts of harmful emissions and wastes which can be occurred in gaseous, liquid and solid forms. Most of the gaseous emissions are formed during operation phase. In this study, three scenarios are developed based on real shipping data in order to investigate the effect of ship size to air emissions formed during operation phase. In the first scenario, Ship A carries 170,000 tons of goods, per se. In the second scenario, Ship B and Ship C carry 170,000 tons of goods in the same route with Ship A. In the third scenario, Ship B, Ship D and Ship E carry the same amount of load in the same route with the previous scenarios.
\end{abstract}

Keywords Shipping, Shipping Emissions, Emission Routing, Ship Size

\section{Introduction}

In the latest report, United Nations Conference on Trade and Development (UNCTAD) indicated that from 2013 to 2014, world seaborne trade grew from 9,514 million tons to 9,842 million tons, which corresponds to a increase by $3.4 \%$. In the same report it was also estimated that in 2015, the world's commercial fleet consisted of 89,464 vessels, with a total tonnage of 1.75 billion DWT, which was 1.69 billion DWT in 2014 [1]. Intergovernmental Panel on Climate Change (IPCC) published a Special Report on Emissions Scenarios (SRES) in 2000. The report mainly focused on six sources (population, economy, technology, energy, land use and agricultural activities) and their effect on future emission scenarios in global, regional, economic and environmental perspectives. According to the results, it is estimated that the number of ships will increase by $40.3 \%$ in 2050 and the total fuel consumption will increase by $43.5 \%$, correspondingly [2]. Thus, shipping emissions will cause inevitable and remarkable problems in the future as it is now.
There are different types of fossil fuels used by marine vehicles. Heavy fuel oil (HFO), marine diesel oil (MDO), marine gas oil (MGO) are the most common liquid fuels for marine engines. Although their purity grades are very different, due to the carbon content and similar combustion processes, the end-products of these fuels are almost same.

It is estimated that there are almost 450 different types of gaseous emissions [3]. Carbon-based gaseous emissions such as carbon dioxide $\left(\mathrm{CO}_{2}\right)$, carbon monoxide $(\mathrm{CO})$ and black carbon $(\mathrm{BC})$ have the greatest share and their dependency to fuel type is less than other emission types. Sulfur oxides $\left(\mathrm{SO}_{\mathrm{x}}\right)$ and nitrogen oxides $\left(\mathrm{NO}_{\mathrm{x}}\right)$ are other gaseous emissions. Although the formation of sulfur oxides is mainly based on the sulfur content of the fuel, nitrogen oxide formation depends on the characteristics of combustion process. Particulate matter (PM) is another important pollutant and it consists of soot, ash and micro-sized carbon particles. PM is strongly related with $\mathrm{SO}_{\mathrm{x}}$.

According to the latest report of International Maritime Organization (IMO), total shipping activities are responsible for 938 million tons of $\mathrm{CO}_{2}$ and 961 million tons of $\mathrm{CO}_{2} \mathrm{e}$ for combining $\mathrm{CO}_{2}, \mathrm{CH}_{4}$ and $\mathrm{N}_{2} \mathrm{O}$, which are identified as greenhouse gases (GHG's) in Kyoto Protocol. Shipping activities have a share of $2.6 \%$ and $2.8 \%$ of global $\mathrm{CO}_{2}$ and $\mathrm{CO}_{2} \mathrm{e}$ production, respectively in 2012 . In the same report, it is also estimated the multi-year (2007-2012) average annual $\mathrm{NO}_{\mathrm{x}}\left(\right.$ as $\left.\mathrm{NO}_{2}\right)$ and $\mathrm{SO}_{\mathrm{x}}\left(\mathrm{SO}_{2}\right)$ are 20.9 million and 11.3 million tones, respectively. The amounts of refrigerant and air conditioning gas related to shipping activities are 15 million tones as $\mathrm{CO}_{2} \mathrm{e}$ [4]. There are some studies that estimate the emissions with different methods.

In recent studies, the estimated $\mathrm{CO}_{2}$ amount is 943.5 million tones [5] and around 1 billion tones, which corresponds to $2-4 \%$ of total $\mathrm{CO}_{2}$ production worldwide [6]. It is also estimated that shipping related $\mathrm{CO}_{2}$ emissions will have a share of $12-18 \%$ of total $\mathrm{CO}_{2}$ production by 2050 [7]. Recent estimations indicate that the amount of shipping related $\mathrm{NO}_{\mathrm{x}}$ emissions are around $6.87 \mathrm{Tg}$ [8] and it is also estimated that shipping is responsible for approximately $15 \%$ of total $\mathrm{NO}_{\mathrm{x}}$ production [9]. The findings of another 
recent study on $\mathrm{NO}_{\mathrm{x}}$ emissions are not completely verified yet but it was indicated that the effect of $\mathrm{NO}_{\mathrm{x}}$ to global warming may more than $\mathrm{CO}_{2}$ [10]. Shipping is also responsible for $6.49 \mathrm{Tg}$ of $\mathrm{SO}_{\mathrm{x}}$ emissions which correspond to $5-8 \%$ total worldwide emissions [8]. In spite of PM is considered as a gas emission, it consists of micro solid particulates which may be smaller than $2.5 \mu \mathrm{m}$. Shipping activities are thought to be responsible for 0.9-1.7 million tons of PM, annually [11]. Although the shipping-related air emissions have not the greatest share of worldwide production, the main problem is the major part of these emissions is formed near the regions with intense population. It is estimated that 70,44 and $36 \%$ of ship traffic occur within 200, 50 and 25 nautical miles from shore [12]. Some recent studies focused on developing emission inventories from oceangoing vessels $[13,14,15,16]$. Besides, weather routing is another important method in order to optimize the ships' emissions $[17,18]$.

\section{Materials and Methods}

Table 1. Main characteristics of ships

\begin{tabular}{|c|c|c|c|c|c|}
\hline $\begin{array}{c}\text { Main } \\
\text { Characteristics }\end{array}$ & Ship A & Ship B & Ship C & Ship D & Ship E \\
\hline LOA & $290 \mathrm{~m}$. & $230 \mathrm{~m}$. & $230 \mathrm{~m}$. & $200 \mathrm{~m}$. & $180 \mathrm{~m}$. \\
\hline B & $45 \mathrm{~m}$. & $32 \mathrm{~m}$. & $32 \mathrm{~m}$. & $32 \mathrm{~m}$. & $25 \mathrm{~m}$. \\
\hline T & $18 \mathrm{~m}$. & $14 \mathrm{~m}$. & $14 \mathrm{~m}$. & $13 \mathrm{~m}$. & $10 \mathrm{~m}$. \\
\hline DWT & $\begin{array}{c}170,000 \\
\text { tons }\end{array}$ & $\begin{array}{c}85,000 \\
\text { tons }\end{array}$ & $\begin{array}{c}85,000 \\
\text { tons }\end{array}$ & $\begin{array}{c}55,000 \\
\text { tons }\end{array}$ & $\begin{array}{c}30,000 \\
\text { tons }\end{array}$ \\
\hline
\end{tabular}

The purpose of this study is to estimate the total emission amounts of five different bulk carriers, which have the same carrying capacity for different scenarios, in a real voyage.
While Ship A is 170,000 DWT, Ship B and Ship C are 85,000 DWT. Ship D is 55,000 DWT and Ship E is 30,000 DWT. Table 1 presents the main characteristics of these five ships.

There are three emission estimation methodologies: Fuel Consumption (FC), Engine Power (EP) and Energy (E) Methods. FC Method is based on real fuel consumption data. It may be the most reliable above all because it is based on noon reports, which are recorded daily by ships. EP Method is based on engine power, engine load and working hours of a ship. It is the most common method because the data is the easiest to reach. However, the engine load and specific fuel consumption of the engine must be considered carefully. E Method is based on the calorific values of the fuel burnt, thus, it is also based on fuel consumption data. All three methods can be used to calculate the emissions and three of all can be considered as correct.

The equations for $\mathrm{FC}$ and EP Methods are offered as follow, respectively [19].

$$
\begin{gathered}
E_{\text {Trip }, i, j, m}=\sum\left(F C_{j, m, p} * E F_{i, j, m, p}\right) \\
E_{\text {Trip }, i, j, m}=\sum\left[T P \sum\left(P_{e} * L F_{e} * E F_{e, i, j, m, p}\right)\right]
\end{gathered}
$$

Equation (3) can be used for E Method.

$$
E_{\text {Trip }, i, j, m, p}=\sum F C_{j, m, p} * C V_{m} * E F_{i, j, m, p}
$$

All ships completed approximately 6600 nautical mile route. The routes are shown in Table 2 .

Emission factors are used in order to calculate the total emissions. Different emission factors are determined for different estimation methods and Table 2 presents these

\begin{tabular}{|c|c|c|c|c|c|c|c|c|c|}
\hline & & & $\mathrm{CO}_{2}$ & $\mathrm{CO}$ & $\mathrm{NO}_{\mathrm{x}}$ & $\mathrm{SO}_{\mathrm{x}}$ & $\mathrm{PM}$ & $\mathrm{CH}_{4}$ & NMVOC \\
\hline \multirow{4}{*}{$\begin{array}{l}\text { Fuel consumption } \\
\text { method }^{\mathrm{a}}\end{array}$} & \multirow{2}{*}{ Main engine } & $\mathrm{HFO}$ & 3179 & 2.545 & 87.136 & 46 & 6.667 & 0.0308 & 1.525 \\
\hline & & $\mathrm{MDO} / \mathrm{MGO}$ & 3179 & 2.703 & 91.561 & 8 & 1.081 & 0.0324 & 1.622 \\
\hline & \multirow{2}{*}{ Aux. engine } & HFO & 3179 & 3.924 & 61.728 & 46 & 2.203 & 0.0176 & 0.871 \\
\hline & & $\mathrm{MDO} / \mathrm{MGO}$ & 3179 & 4.127 & 62.440 & 8 & 0.922 & 0.0184 & 0.916 \\
\hline \multirow{4}{*}{$\begin{array}{l}\text { Engine power } \\
\text { method }^{\text {s }}\end{array}$} & \multirow{2}{*}{ Main engine } & $\mathrm{HFO}$ & 620 & 0.5 & 18.1 & 9 & 1.3 & 0.006 & 0.3 \\
\hline & & MDO/MGO & 588 & 0.5 & 17 & 1.5 & 0.2 & 0.006 & 0.3 \\
\hline & \multirow{2}{*}{ Aux. engine } & HFO & 722 & 0.9 & 14 & 10.4 & 0.5 & 0.004 & 0.2 \\
\hline & & $\mathrm{MDO} / \mathrm{MGO}$ & 690 & 0.9 & 13.5 & 1.7 & 0.2 & 0.004 & 0.2 \\
\hline \multirow{4}{*}{ Energy method ${ }^{\mathrm{c}}$} & \multirow{2}{*}{ Main engine } & HFO & 78 & 0.062 & 2.13 & 1.1 & 0.16 & 0.00075 & 0.037 \\
\hline & & $\mathrm{MDO} / \mathrm{MGO}$ & 74 & 0.063 & 2.14 & 0.19 & 0.025 & 0.00076 & 0.038 \\
\hline & \multirow{2}{*}{ Aux. engine } & HFO & 78 & 0.12 & 1.51 & 1.1 & 0.057 & 0.00045 & 0.022 \\
\hline & & MDO/MGO & 74 & 0.13 & 1.48 & 0.19 & 0.023 & 0.00046 & 0.023 \\
\hline
\end{tabular}
factors for methods, pollutants and engine type.

Table 2. Emission factors [20]

a: $\mathrm{kg} /$ ton

b: $\mathrm{g} / \mathrm{kWh}$

c: $\mathrm{t} / \mathrm{TJ}$ 
Load factors for main and auxiliary engines are presented in Table 3.

Table 3. Load factors [21]

\begin{tabular}{|c|c|c|}
\hline & Main engine & Auxiliary engine \\
\hline At sea & $80 \%$ & $30 \%$ \\
\hline Berthing & $20 \%$ & $40 \%$ \\
\hline Maneuvering & $20 \%$ & $50 \%$ \\
\hline
\end{tabular}

It is also assumed that average maneuvering time for a ship is 0.06 days or 1.44 hours for a journey [22]. All ships' main and auxiliary engines are classified as slow speed diesel engine and medium speed diesel engine, respectively. It is that main engine can use both HFO and MDO; however, auxiliary engine can use HFO, MDO and MGO. Because MDO is not used by any ships, it can be precipitated that consumed MGO is used by only auxiliary engine. It is also assumed that main engine isn't run during berthing. Thus, HFO, which is consumed during berthing, is actually used during maneuvering.

According to a recent study, $90 \%$ and $55 \%$ of HFO is consumed by main engine during operation and maneuvering, respectively [23].

\section{Conclusions}

The total amounts of air pollutants for three scenarios are presented in Table 4.

Table 4. Emission Types and Amounts

\begin{tabular}{|c|c|c|c|c|c|c|c|c|c|}
\hline & \multicolumn{3}{|c|}{ SCENARIO-1 } & \multicolumn{3}{c|}{ SCENARIO-2 } & \multicolumn{3}{c|}{ SCENARIO-3 } \\
\hline & $\mathrm{FC}$ & $\mathrm{EP}$ & $\mathrm{E}$ & $\mathrm{FC}$ & $\mathrm{EP}$ & $\mathrm{E}$ & $\mathrm{FC}$ & $\mathrm{EP}$ & $\mathrm{E}$ \\
\hline $\mathrm{CO}_{2}$ & 3497,24 & 4422,52 & 3485,42 & 4903,28 & 6557,71 & 4884,39 & 6400,27 & 8227,94 & 6400,68 \\
\hline $\mathrm{CO}$ & 2,96 & 3,7 & 3,047 & 4,15 & 5,54 & 4,27 & 5,46 & 7,01 & 5,69 \\
\hline $\mathrm{NO}_{\mathrm{x}}$ & 92,77 & 126,48 & 92,16 & 130,16 & 186,54 & 129,28 & 169,18 & 233,08 & 168,64 \\
\hline $\mathrm{SO}_{x}$ & 50,44 & 60,79 & 48,97 & 70,56 & 88,79 & 68,51 & 90,96 & 110,16 & 88,4 \\
\hline $\mathrm{PM}$ & 6,79 & 8,76 & 6,63 & 9,51 & 12,78 & 9,31 & 12,26 & 15,86 & 12,02 \\
\hline $\mathrm{CH}$ & 0,03 & 0,04 & 0,03 & 0,04 & 0,06 & 0,04 & 0,05 & 0,07 & 0,05 \\
\hline $\mathrm{NMVOC}$ & 1,59 & 2,08 & 1,61 & 2,24 & 3,06 & 2,26 & 2,95 & 3,83 & 2,95 \\
\hline
\end{tabular}

Figure 1 summarizes the total amounts of emissions.

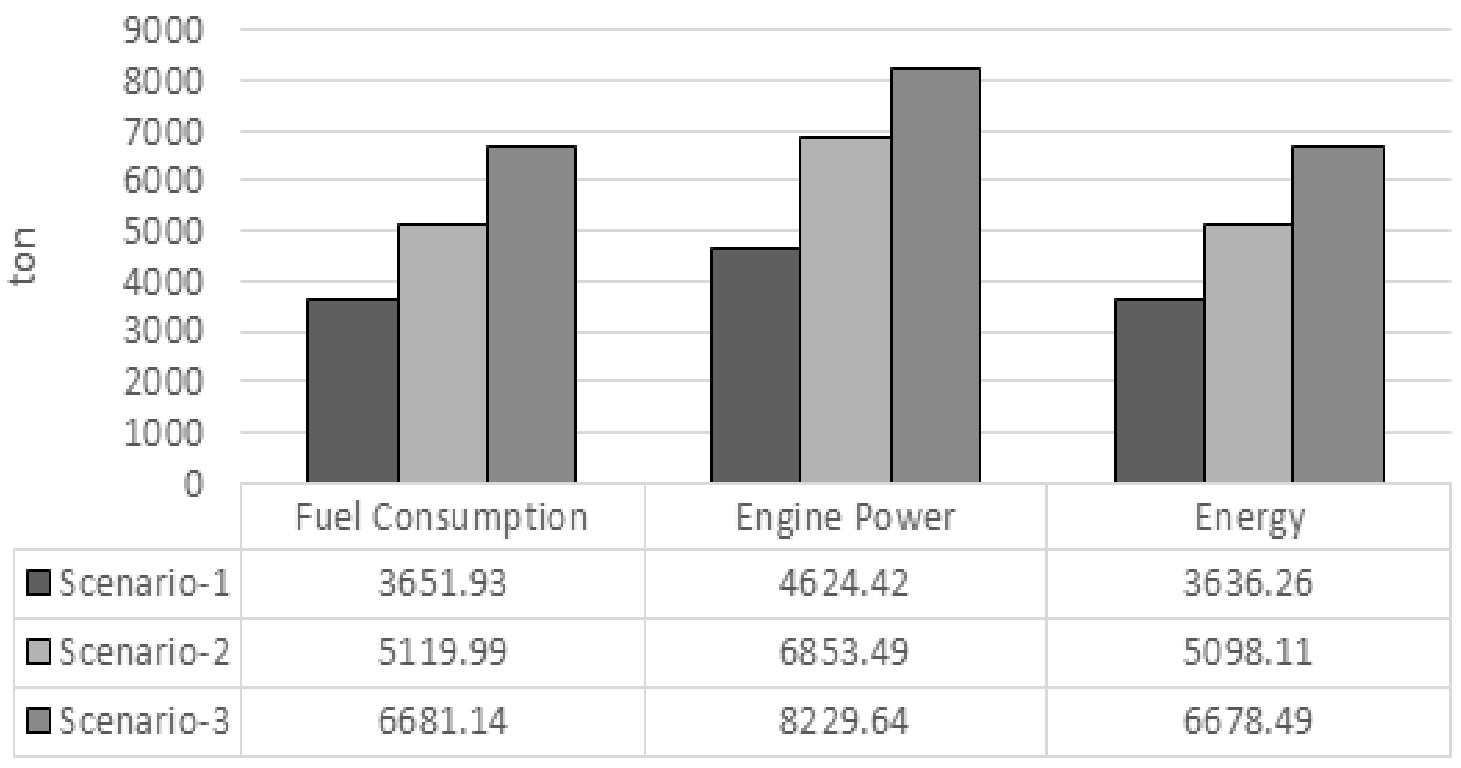

Figure 1. Total Emissions of Different Scenarios

Figure 2 presents the emission/DWT ratios, which are more explanatory and reliable data for emission amounts. 


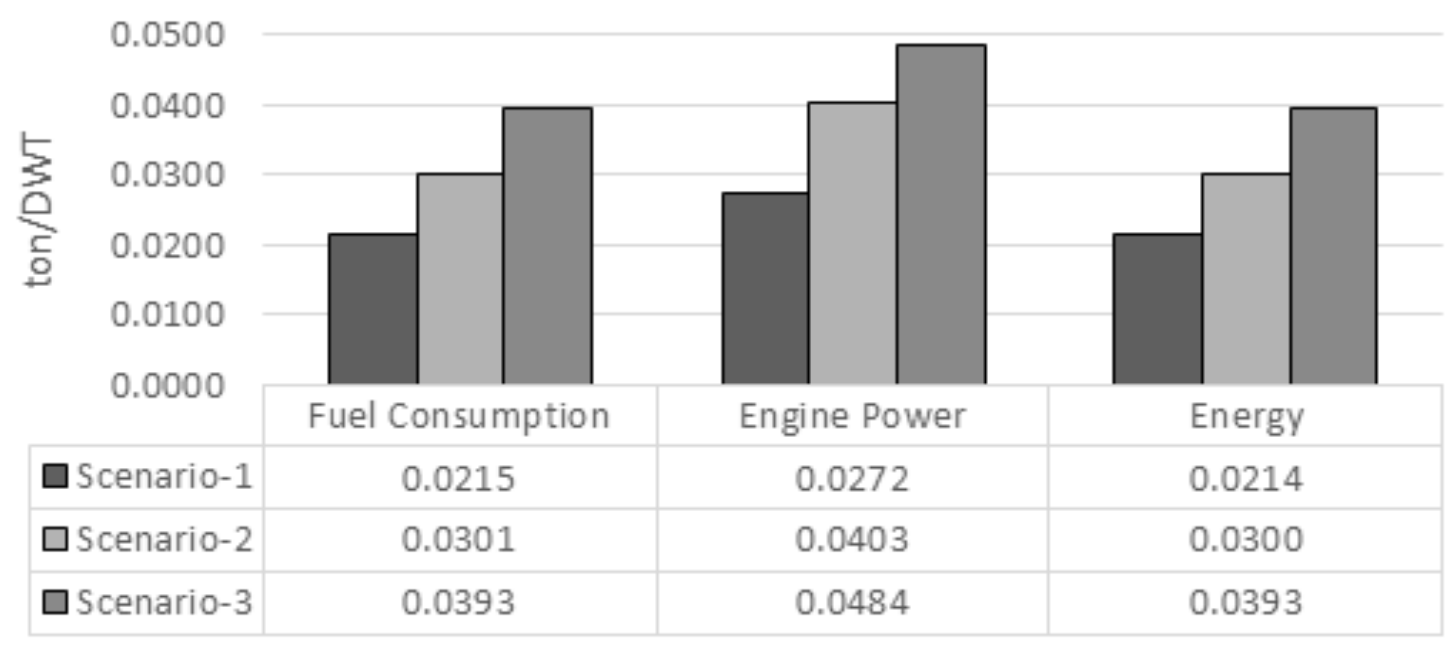

Figure 2. Emission/DWT Ratios

Emission estimation methods for shipping provide an idea on the total emissions, roughly. Due to the uncertainties of obtaining the real fuel consumption or engine working hour data and other factors that have effect on emissions; developing certain emission factors is extremely hard. Thus, these methods can be called as approaches and the results are just estimations. On the other hand, innovative technologies and novel approaches are being developed in order to obtain more reliable and accurate emission factors. All three methodologies that are explained in this study can be assumed as correct.

Although the air emissions caused by shipping activities are relatively low comparing the other sources such as land emissions (including factories and motor vehicles), they must be focused because most of the shipping emissions occur near big cities with high population density. There are many different ways to reduce the emissions and improving the ship size is one of them. As it can be seen in Figure 1 and Figure 2, bigger ships produce lesser emissions. Considering the load amount, bigger ships are much more efficient in terms of emission/DWT ratios. Thus, it is obvious that greater ships are more environmental-friendly. Although the need for energy and material consumption are more during manufacturing of bigger ships, taking into account all life cycle, they are more efficient on energy and thus, emission issues.

\section{REFERENCES}

[1] UNCTAD, Review of Maritime Transport, ISBN 978-92-1-112892-5, 2015.

[2] IPCC, IPCC Special Report Emissions Scenarios, Summary for Policymakers, ISBN 92-9169-113-5, 2000.

[3] V. Andreoni, A. Miola, A. Perujo. Cost Effectiveness Analysis of the Emission Abatement in the Shipping Sector Emissions, European Commission Joint Research Center,
Institute for Environment and Sustainability, ISBN 978-92-79-11280-5, 2008.

[4] IMO, 2014. Third IMO Greenhouse Gas Study, 2015.

[5] H. N. Psaraftis, C.A. Kontovas. $\mathrm{CO}_{2}$ Emission Statistics for the World Commercial Fleet, WMU Journal of Maritime Affairs, Vol. 8, 1-25, 2009.

[6] E. Tzannatos. Ship Emissions and Their Externalities for Greece, Atmospheric Environment, Vol. 44, 2194-2202, 2010.

[7] N. Heitmann, S. Khalilian. Accounting for $\mathrm{CO}_{2}$ Emissions from International Shipping: Burden Sharing under Different UNFCCC Allocation Option and Regime Scenarios, Kiel Working Paper No. 1665, 2010.

[8] J.J. Corbett, H. W. Köhler. Updated Emissions from Ocean Shipping, Journal of Geophysical Research, Vol. 108, 2003.

[9] V. Eyring, H. W. Köhler, J. van Aardenne, A. Lauer. Emissions from International Shipping: 1 the Last 50 Years, Journal of Geophysical Research, Vol. 110, 2005.

[10] R.F. Henningsen. Study of Greenhouse Gas Emissions from Ships, Final Report to the IMO, MARINTEK, 2000.

[11] Ø. Endresen, E. Sørgard, J.K. Sundet, S.B. Dalsøren, I.S.A. Isaksen, T. F. Berglen, G. Gravir. Emissions from International Sea Transportation and Environmental Impact, Journal of Geophysical Research, Vol. 108, 2003.

[12] Ø. Buhaug, J.J. Corbett, Ø. Endresen, V. Eyring, J. Faber, S. Hanayama, D.S. Lee, D. Lee, H. Lindstad, A.Z. Markowska, A. Mjelde, D. Nelissen, J. Nilsen, C. Pålson, J.J. Winebrake, W. Wu, K. Yoshida. Second IMO GHG Study, International Maritime Organization, London, UK, 2009.

[13] A. Kasper, S. Aufdenblatten, A. Forss, M. Mohr, H. Burtscher. Particulate Emissions from a Low-Speed Marine Diesel Engine, Aerosol Science Technology, Vol. 41, 24-32, 2007.

[14] A. Petzold, J. Hasselbach, P. Lauer, R. Baumann, K. Franke, C. Gurk, H. Schlager, E. Weingartner. Experimental Studies on Particle Emissions from Cruising Ship, Their Characteristic Properties, Transformation and Atmospheric Lifetime in the Marine Boundary Layer, Atmospheric Chemistry and Physics, Vol. 7(15), 105-115, 2007. 
[15] G. Chen, G. Huey, M. Trainer. An Investigation of the Chemistry of Ship Emission Plumes during ITCT 2002, Journal of Geophysical Research, Vol. 110, D10S90, 2005.

[16] V. Eyring, I. S. A. Isaksen, T. Berntsen, W. J. Collins, J. J. Corbett, Ø. Endresen, R. G. Grainger, J. Moldanova, H. Schlager, D. S. Stevenson. Transport Impacts on Atmosphere and Climate: Shipping, Atmospheric Environment, Vol. 44, 4735-4771, 2010.

[17] Y.H. Lin, M.C. Fang, R. W. Yeung. The Optimization of Ship Weather-Routing Algorithm Based on the Composite Influence of Multi-Dynamic Elements, Applied Ocean Research, Vol. 43, 184-194, 2013.

[18] M. C. Fang, Y.H. Lin. The Optimization of Ship Weather-Routing Algorithm Based on the Composite Influence of Multi-Dynamic Elements (II): Optimized Routings, Applied Ocean Research, Vol. 50, 130-140, 2015.

[19] C. Trozzi. Emission Estimation Methodology for Maritime Navigation, US EPA $19^{\text {th }}$ International Emissions Inventory Conference, 2010.
[20] D. Cooper, T. Gustafsson. Methodology for Calculating Emissions from Ships: 1. Update of Emission Factors, Assignment for Swedish Environmental Protection Agency, 2004.

[21] Entec. European Commission Directorate General Environment, Service Contract on Ship Emissions: Assignment, Abatement and Market-based Instruments, Task 2-General Report, 2005.

[22] G. Lonati, S. Cernuschi, S. Sidi. Air Quality Impact Assessment of at-Berth Ship Emissions: Case-Study for the Project of a New Freight Port, Science of the Total Environment, Vol. 409, 192-200, 2010.

[23] B. Alföldy, J.B. Lööv, F. Lagler, J. Mellqvist, J. Beecken, H. Weststrate, J. Duyzer, L. Bencs, B. Horemans, F. Cavalli, J.P. Putaud, G. Janssens-Maenhout, A.P. Csordás, R. Van Grieken, A. Borowiak, J. Hjorth. Measurements of Air Pollution Emission Factors for Marine Transportation in SECA, Atmospheric Measurement Techniques, Vol. 6, 1777-1791, 2013. 